\title{
Intra-hippocampal administration of ZIP alleviates depressive and anxiety-like responses in an animal model of posttraumatic stress disorder
}

\author{
Li-Li Ji' , Lei Tong ${ }^{1}$, Bao-Ku Xu' ${ }^{1}$, Chang-Hai Fu' ${ }^{1}$, Wan Shu' ${ }^{1}$ Jun-Bo Peng ${ }^{2}$ and Zhen-Yu Wang ${ }^{1 *}$
}

\begin{abstract}
Background: Given that impairment of fear extinction has been implicated in the pathogenesis of posttraumatic stress disorder (PTSD), effective pharmacological interventions that facilitate fear extinction may provide alternative strategies to conventional treatment. It is generally accepted that the zeta inhibitory peptide (ZIP), a controversial inhibitor of protein kinase M zeta (PKMC), could erase certain types of previously established long-term memories. However, it is unclear whether ZIP administration may alleviate PTSD-associated depressive and anxiety-like abnormalities.
\end{abstract}

Methods: Here we developed a re-stressed single-prolonged stress (SPS) paradigm, a modified prevalent animal model of PTSD, and assayed the expressions of PKM in the hippocampus after SPS procedure. Next, Seven days prior to re-stress, ZIP was injected into the hippocampus, and the depressive and anxiety-like behavior was examined by the subsequent forced swim (FS), open-field and elevated plus maze (EPM) test.

Results: Rats given ZIP prior to FS exhibited a reduction of immobility time in FS test, and more open arms (OA) entries and longer OA duration in EPM. They also spent longer time in the center of the open field.

Conclusions: Our results suggested that re-stressed SPS could reproduce behavioral alteration similar to that observed in patients with PTSD, and these behavioral symptoms co-morbid with PTSD could be effectively alleviated by the intro-hippocampal administration of ZIP.

Keywords: Posttraumatic stress disorder, Single prolonged stress, ZIP, PKM

\section{Background}

Posttraumatic stress disorder (PTSD) can develop following exposure to a severe traumatic event or natural disasters [1]. It is a psychopathological response to the traumatic stressor and is characterized by intense memories in which patients re-experience their original traumatic experiences, as well as avoidance of the traumarelated stimuli, and increased arousal [2,3]. However, the precise mechanism of the intricate biological and psychological symptom remains elusive. The neural structures involved in the pathophysiology of PTSD belong to the limbic system, a region important for emotional processing in both humans and animals [4]. The three brain

\footnotetext{
*Correspondence: zywang@live.cn

'Department of Anatomy, College of Basic Medical Sciences, China Medical University, Shenyang 110001, People's Republic of China

Full list of author information is available at the end of the article
}

regions within the limbic system most clearly altered in PTSD have been identified as the prefrontal cortex, the amygdala and the hippocampus, among which, the hippocampus plays a key role in explicit memories of traumatic events and in mediating learned responses to contextual cues [5-8]. Indeed, hippocampal reduction has been found in patients with PTSD in a majority of structural neuroimaging studies [9-13].

Single-prolonged stress (SPS), a currently prevalent animal model of PTSD, has been extensively developed and employed in the investigation of PTSD [14-16]. SPS consists of three different stress paradigms: restraint for $2 \mathrm{~h}$, forced swim for $20 \mathrm{~min}$, and ether anesthesia. SPS exposure results in impaired extinction of contextual fear [16], enhanced glucocorticoid negative feedback, and enhanced anxiety-like behavior [17,18], partially 
resembling the pathophysiological and behavioral abnormalities of PTSD [19].

The persistence of traumatic fear memories in PTSD suggests this disorder might be associated with extinction deficits [20-23], consistent with an interpretation of PTSD as a syndrome of deficient extinction ability [24]. Thus, any intervention facilitating fear extinction or disrupting fear memory may have a therapeutic value on PTSD. Over the past two decades, multiple lines of evidence have indicated that protein kinase $\mathrm{M}$ zeta (PKM)), a brain-specific atypical protein kinase $\mathrm{C}(\mathrm{PKC})$ isoform, is required for long term potentiation (LTP) and the maintenance of several forms of memory, including the hippocampusdependent memory [25-31]. Overexpression of PKM could enhance long-term memory, while pharmacologically blocking PKM $\zeta$ by myristoylated zeta-pseudosubstrate inhibitory peptide (ZIP) could erase previously established long-term memories [26,28,32-35]. Although currently there is still an ongoing debate on the critical issue of PKM $\zeta$ being a major memory maintenance molecule and ZIP as a specific PKM $\zeta$ inhibitor [34,36-40], there is a consensus among researchers that ZIP can disrupt certain types of memory $[29,30,33,34,37,41]$. Thus the mechanism of ZIP on memory disruption is far from clear. Nevertheless, PKM $\zeta$ remains largely to be the target of ZIP infusions [42]. These inconsistent findings open up a variety of opportunities to gain additional insight into the action of ZIP.

As mentioned above, most research on ZIP has been applied to a certain kind of conditioned learning and memory paradigm to investigate its role on memory disruption. Since SPS has been shown to disrupt the retention stage of fear extinction [20], it is interesting to know whether ZIP may have an impact on SPS procedure, especially the depressive and anxiety-like behavior, representing the core symptom of PTSD-related abnormalities. As a result, the present study used a classic SPS model, but after the last quiescent period, the rats were re-exposed to the forced swim component of SPS, which served as the re-stress component of the paradigm. Next, the expression of PKM $\zeta$ in the hippocampus of SPS rats was assayed. Finally, ZIP was microinfused into the hippocampus seven days prior to re-stress, and subsequent forced swim, openfield and elevated plus maze test were performed, so as to assess the effect of ZIP on the PTSD-associated symptoms of depressive and anxiety-like behavior.

\section{Materials and methods}

Animals

Male Sprague-Dawley rats (7 - 8 weeks old) weighing 200 - $250 \mathrm{~g}$ were purchased from the Experimental Animal Center of China Medical University (Shenyang, China). Animals were housed singly under a $12: 12$-h light dark cycle, with food and water freely available. Following an adaptation period of at least 7 days, the experimental procedures were undertaken. All procedures complied with the National Institutes of Health Guide for the care and use of laboratory animals and were approved by the Animal Care and Use Committee of China Medical University.

\section{Experimental groups and the SPS model}

The rats were randomly assigned to seven groups (Control, SPS 7d, SPS 14d, Control + Saline, Control + ZIP, SPS + Saline, and SPS + ZIP, 12 rats per group). The SPS procedure was conducted as described previously [1,17], with slight modifications. Briefly, Rats were restrained for $2 \mathrm{~h}$ inside a disposable restraint holder (diameter $58 \mathrm{~mm}$, length $150 \mathrm{~mm}$ ). Next, they were individually placed in a clear acrylic container $(600 \times$ $400 \times 500 \mathrm{~mm})$ filled two thirds with water $\left(24^{\circ} \mathrm{C}\right)$, and forced to swim for $20 \mathrm{~min}$. Following a 15 -min recuperation, animals were exposed to diethyl ether until loss of consciousness and left undisturbed in their cages for 7 or 14 days according to their groups (Figure 1).

\section{Surgery}

Rats were anaesthetized with chloral hydrate ( $400 \mathrm{mg} / \mathrm{kg}$ i.p) and prepared with bilateral stainless steel 26-gauge cannulae aimed at the dorsal hippocampus using stereotaxic coordinates (anteroposterior, $-3.6 \mathrm{~mm}$; medial-lateral, $\pm 3.1 \mathrm{~mm}$; dorsoventral, $-2.4 \mathrm{~mm}$ ) relative to bregma. Cannulae were secured to the skull with stainless steel screws and dental cement. Stainless steel obdurators remained in the cannulae when rats were not being injected to prevent occlusion. Each rat was given a recovery period of at least $7 \mathrm{~d}$ before the experiments.

\section{Drug infusions}

ZIP (Abcam, Cambridge, MA, USA) was dissolved in sterile saline to a concentration of $10 \mathrm{nmol} / \mu \mathrm{l}$. ZIP or saline were infused into the dorsal hippocampus $(1 \mu \mathrm{l}$ per hemisphere) via a microinjector (28 gauge) connected to a microinfusion pump (Stoelting Co., Wood Dale, IL, USA) at a rate of $0.25 \mu \mathrm{l}$ per min. The injector remained connected for an additional 1 min to allow for drug diffusion away from the tip of the cannula.

\section{Forced swim test (FST)}

Rats were individually forced to swim in an open cylindrical container (diameter $20 \mathrm{~cm}$, height $40 \mathrm{~cm}$ ) filled to two-thirds with $24^{\circ} \mathrm{C}$ fresh water. The total duration of immobility during the 5-min test was scored by a trained individual blinded to the experimental group. Each mouse was judged to be immobile when it ceased struggling and remained floating motionless in the water, making only those movements necessary to keep its head above water. 


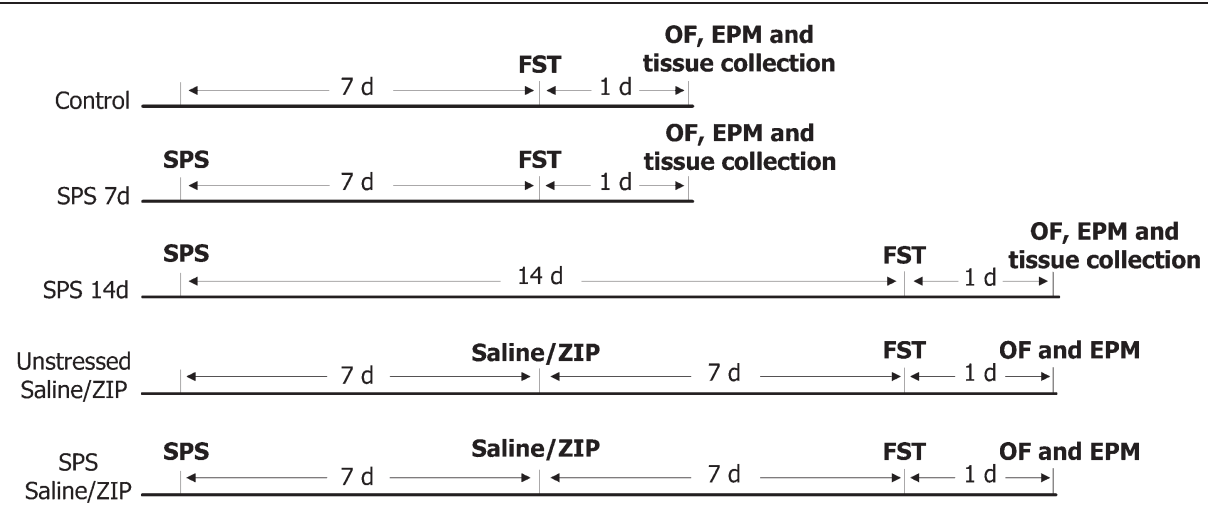

Figure 1 Schematic of experimental design. Rats were exposed to control handling or SPS, followed by 7 or 14 days of quiescent period with no manipulation. Next, for the Control, SPS 7d and SPS 14d groups, subsequent forced swim (FS), open-field (OF) and elevated plus maze (EPM) test were performed, and the rats were finally sacrificed for Western blotting and real-time RT-PCR. For the Control + Saline, Control + ZIP, SPS + Saline, and SPS + ZIP groups, ZIP or saline were administrated after the 7 days of quiescent period of SPS. Following another 7 days interval, FS, OF and EPM were performed.

\section{Open-field test (OFT)}

The open-field test was used to quantify locomotor, exploratory and anxiety-like behavior. The apparatus was a black Plexiglas enclosure measuring $50 \times 50 \times 50$ $\mathrm{cm}$ with a red fluorescent light illumination over the center of the arena. After $30 \mathrm{~min}$ of acclimation in the room, rats were placed in a central start position in the open arena and allowed to explore for $5 \mathrm{~min}$, during which their behavior was recorded and analyzed with "SuperMaze" software (Softmaze Co., Shanghai, China). The arena was cleaned with $70 \%$ ethanol after each session and individual rat was tested only once.

\section{The elevated plus maze (EPM)}

The EPM apparatus consisted of two opposing open and two opposing closed arms $(50-\mathrm{cm}$ arms, elevated $50 \mathrm{~cm}$ off the ground). Animals were placed into the center $(10 \times 10 \mathrm{~cm})$ of the maze facing an open arm and behavior was recorded for $5 \mathrm{~min}$. The number of arm entries and time spent in open and closed arms were analyzed with "SuperMaze" software (Softmaze Co.). The percentage of time spent in the open arms and percentage of entries into the open arms relative to total (open + closed) arm were quantified as assessments of anxiety.

\section{Western blot analysis}

The rats of each group were decapitated rapidly and the hippocampi were dissected on ice. The samples were homogenized with loading buffer containing 200 mM Tris- buffered saline, $4 \%$ sodium dodecyl sulfate, $20 \%$ glycerol and 10\% 2-mercaptoethanol, and were denatured by boiling for $3 \mathrm{~min}$. The protein fraction $(30 \mu \mathrm{g} / \mathrm{lane})$ extracted from each sample was separated by $12 \%(\mathrm{w} / \mathrm{v})$ gradient sodium dodecyl sulfate-polyacrylamide gel electrophoresis and transferred to a $0.45-\mu \mathrm{m}$ polyvinylidene fluoride (PVDF) membrane (Millipore, Billerica, MA, USA). Following blocking with $5 \%(\mathrm{w} / \mathrm{v})$ skimmed milk in $0.05 \%$ TBS with Tween-20 (TBST) at room temperature for $2 \mathrm{~h}$ and incubation with a rabbit polyclonal antibody against rabbit polyclonal antibody against PKC (1:5000; Abcam, Cambridge, MA, USA) overnight at $4^{\circ} \mathrm{C}$, the membrane was incubated with anti-rabbit IgG-HRP (1:5000; ZSBio, Beijing, China) secondary antibodies for another $2 \mathrm{~h}$ at room temperature. Blots were scanned with a ChemiDoc XRS + image analysis system (Bio-Rad Laboratories, Hercules, CA, USA) and analyzed with Image J software (National Institutes of Health, Bethesda, MD, USA).

\section{mRNA extraction and quantitative real-time RT-PCR analysis}

For detecting the mRNA levels of PKM $\zeta$ and PKC $\zeta$, quantitative real-time RT-PCR was conducted. Total RNA from dissected hippocampus was isolated with TRIzol (Invitrogen, Carlsbad, CA, USA) according to the manufacturer's instructions. The primer sequences (designed and synthesized by Sangon Biotech Co., Shanghai, China) were presented in Table 1. Complementary DNA (cDNA) was obtained from total RNA using PrimeScript ${ }^{\mathrm{Tm}}$ RT

Table 1 Sense and antisense primers used to amplify each CDNA of interest

\begin{tabular}{|c|c|c|}
\hline & Sense primer $\left(5^{\prime}-3^{\prime}\right)$ & Antisense primer $\left(5^{\prime}-3^{\prime}\right)$ \\
\hline PKM & 5'-CCATGCCCAGCAGGACCACC-3' & 5'-TGAAGGAAGGTCTACACCATCGTTC-3' \\
\hline PKCद & 5'-CCTTCTATTAGATGCCTGCTCTCC-3' & 5'-TGAAGGAAGGTCTACACCATCGTTC-3' \\
\hline GAPDH & 5'-ACATGGTCTACATGTTCC-3' & 5'-CAGATCCACAACGGAATAC-3' \\
\hline
\end{tabular}


Reagent Kit (TaKaRa Biotech, Dalian, China). Real-time quantitative PCR analysis was performed on the ABI 7500 Real-time PCR System (Applied Biosystems Inc., Foster City, CA, USA), using SYBR Premix Ex Taq ${ }^{\text {Tx }}$ kit (TaKaRa Biotech). Triplicate reactions were run per sample. Relative quantification of gene expression was determined based on the threshold cycle $(\mathrm{Ct})$ value for each PCR reaction. $\Delta \mathrm{Ct}$ values represent normalized target gene levels with respect to the internal control (GAPDH). Relative quantification of gene expression (relative amount of target RNA) was determined by the $2^{-\Delta \mathrm{Ct}}$ method. $\Delta \Delta \mathrm{Ct}$ values were calculated as the $\Delta \mathrm{Ct}$ of each sample minus the mean $\Delta \mathrm{Ct}$ of the calibrator samples (control group). The fold change in expression was calculated with the equation $2^{-\Delta \Delta C t}$. All primer sets had comparable efficiency of amplification. After amplification, the specificity of the PCR products was verified by a melting curve analysis to ensure that a single product of expected melt curve characteristics was obtained.

\section{Statistical analysis}

All data were presented as mean \pm S.E.M. unless otherwise specified, and were analyzed with SPSS software (version 20.0; IBM, Armonk, NY, USA) and SigmaPlot (version 12.3; Systat Software Inc., San Jose, CA, USA). Data were analyzed via one-way ANOVA or two-way ANOVA, followed by Tukey's post hoc test or unpaired Student's $t$ test when appropriate. Significant differences between groups were defined by a $p$ value less than 0.05 .

\section{Results}

Effect of ZIP on forced swim behavior following the SPS procedure

To examine the effects of re-exposure to the traumatic stress, seven or fourteen days after SPS stressors were applied, rats were re-stressed by re-exposure to the forced swim component of SPS, and they exhibited enhanced depressive-like behavior evaluated by immobility time in 5-min FST (Figure 2A. Immobility Time (s): Control group 103.3 \pm 15.57 ; SPS 7 d group $157.1 \pm 20.22$; SPS 14d group 153.2 \pm 15.85$)$. One-way ANOVA showed significant differences among the groups in immobility time $(\mathrm{F}(2,33)=35.91, p<0.001)$. Tukey's post hoc analysis revealed that the animals in SPS 7d group or SPS $14 \mathrm{~d}$ group spent a significantly longer percentage of time immobile compared with the control group $(p<0.001$, respectively). There was no significant difference in the immobility time between the two SPS-exposed groups $(p=0.849)$.

Next, the PKM inhibitory peptide (ZIP) was microinfused into the bilateral dorsal hippocampi after the seven undisturbed days for SPS and the animals were left undisturbed for another seven days until the FST was carried out (Figure 2B. Immobility Time (s): Control +

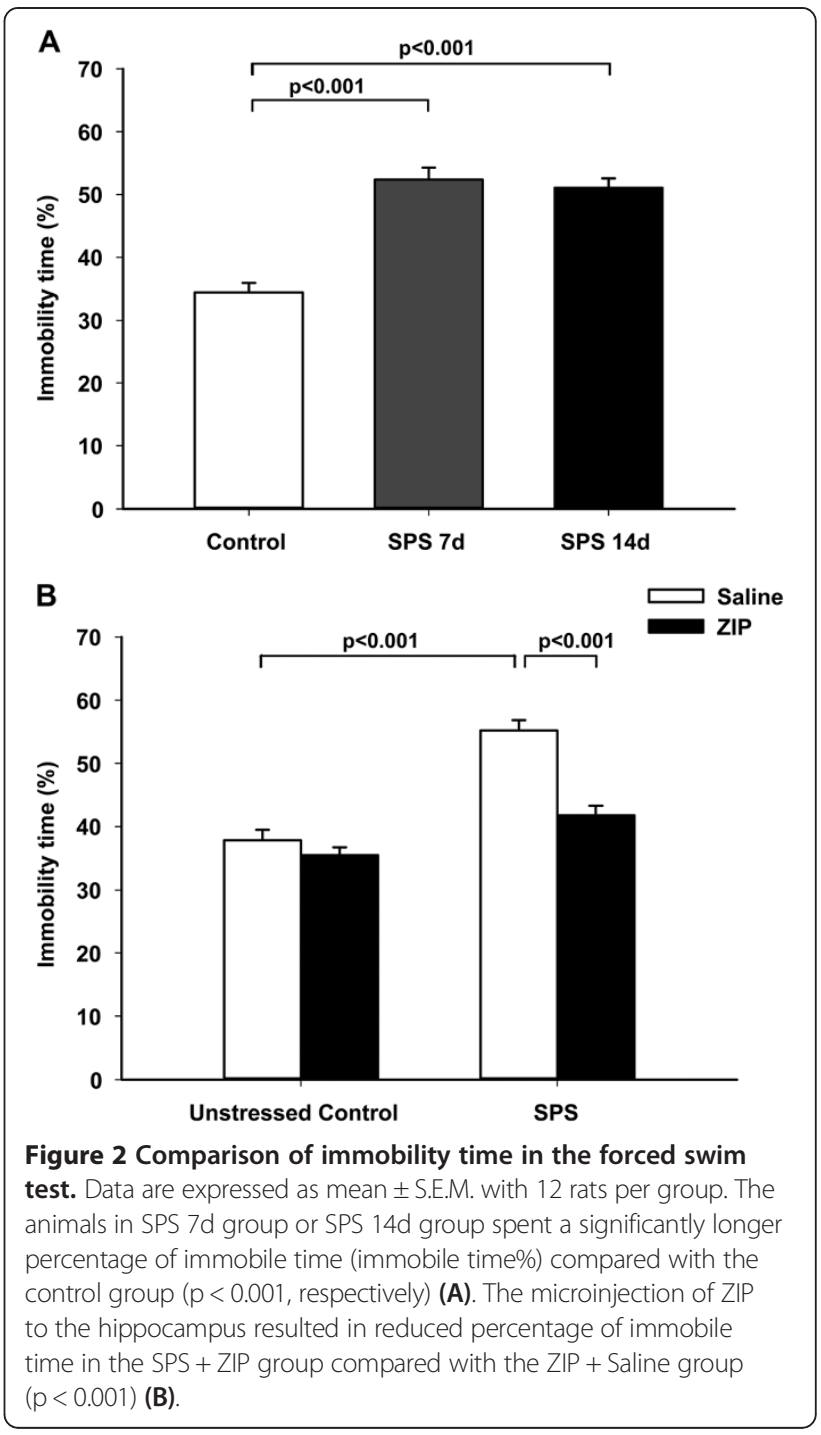

Saline group 113.4 \pm 4.98 ; Control + ZIP group $106.5 \pm$ 3.55; SPS + Saline group $165.7 \pm 4.98$; SPS + ZIP group $125.3 \pm 4.51)$. Two-way ANOVA showed significant effects of SPS $(\mathrm{F}(1,44)=61.185, p<0.001)$, ZIP $(\mathrm{F}(1,44)=$ 27.117, $p<0.001)$, and interaction between SPS and ZIP $(\mathrm{F}(1,44)=13.562, p<0.001)$. Tukey's post hoc analysis revealed that the percentage of immobile time in the SPS + ZIP group was shorter than that in the SPS + Saline group $(p<0.001)$. There was no significant difference in the percentage of immobile time between the SPS + ZIP and Control + Saline groups $(t(22)=1.764, p=0.091)$.

\section{Effect of ZIP on anxiety-like behavior}

Open field test was performed 1 day after FST to examine anxiety-like behavior and locomotion. One-way ANOVA showed significant differences in time in center $(\mathrm{F}(2,33)=5.961, p=0.006)$ and distance in center $(\mathrm{F}(2$, $33)=5.776, p=0.007$ ) among the groups (Figure $3 \mathrm{~A}, \mathrm{~B}$. 

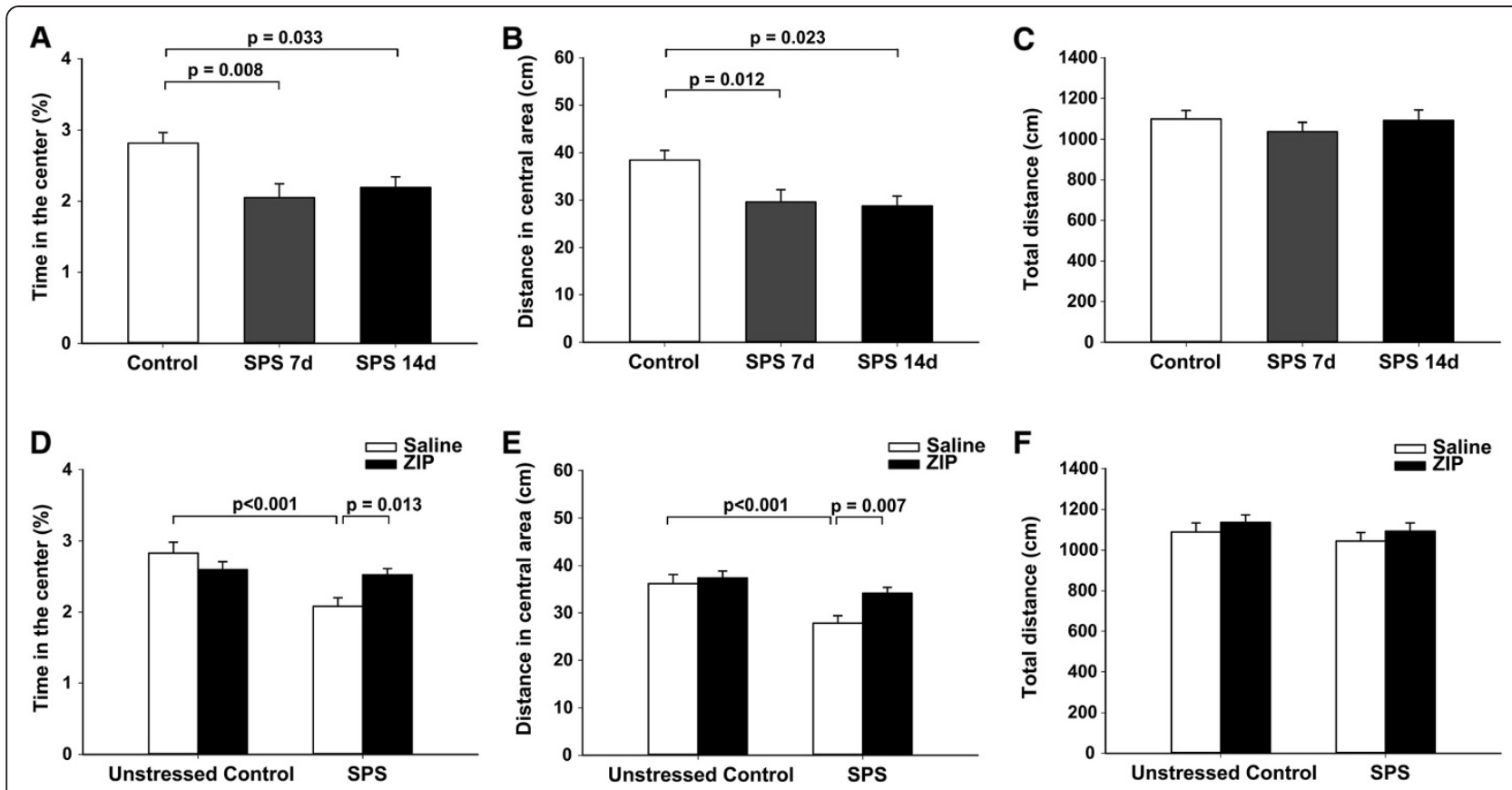

Figure 3 Effect of ZIP on behavior in the open field test. Time in the center ( $\mathbf{A}$ and D), distance in the central area (B and E), and total distance $(\mathbf{C}$ and $\mathbf{F})$. Data are expressed as mean \pm S.E.M. with 12 rats per group.

Time in center (s): Control group $8.5 \pm 0.45$; SPS $7 \mathrm{~d}$ group $6.2 \pm 0.59$; SPS 14d group $6.6 \pm 0.45$. Distance in center (cm): Control group $38.47 \pm 2.017$; SPS $7 d$ group $29.61 \pm 2.582$; SPS $14 d$ group $28.76 \pm 2.069$ ). Post hoc comparison revealed that both the SPS $7 d$ group and the SPS 14d group spent significantly less time in the center than the control group ( $p=0.007, \mathrm{p}=0.032$, respectively) and covered less distance in the center $(p=0.012$, $p=0.023$, respectively). There was no difference between the SPS $7 d$ group and the SPS $14 d$ group $(p>0.05)$. As for the total distance covered, one-way ANOVA did not reveal a significant difference among the three groups $(\mathrm{F}(2,33)=0.505, p=0.608)$, suggesting that SPS exposure did not affect gross motoric behavior (Figure $3 \mathrm{C}$ ).

Next we examined whether the ZIP microinjection could alleviate the anxiety-like behavior evaluated by OFT in rats subjected to SPS. Two-way ANOVA showed significant effects of SPS (F $(1,44)=11.772, p<0.001$; $\mathrm{F}(1,44)=13.699, p<0.001), \quad \mathrm{ZIP} \quad(\mathrm{F} \quad(1,44)=0.770$, $p=0.385 ; \mathrm{F}(1,44)=5.743, p=0.021)$, and interaction between SPS and ZIP $(\mathrm{F}(1,44)=7.877, p=0.007$; F $(1,44)=$ 2.638, $p=0.111)$ in time and distance in the center (Figure 3D, E. Time in center (s): Control + Saline group $8.5 \pm 0.46 ;$ Control + ZIP group $7.8 \pm 0.33 ;$ SPS + Saline group 6.2 \pm 0.36 ; SPS + ZIP group 7.6 \pm 0.26 . Distance in center $(\mathrm{cm})$ : Control + Saline group $36.18 \pm 1.913$; Control + ZIP group $37.38 \pm 1.441 ;$ SPS + Saline group $27.84 \pm$ 1.591; SPS + ZIP group $34.13 \pm 1.236$ ). Tukey's post hoc analysis revealed that the time in the center in the SPS + ZIP group was higher than that in the SPS + Saline group $(p=0.013)$, and the distance in the center in the SPS + ZIP group was more than that in the SPS + Saline group $(p=0.007)$, indicative of lower anxiety. There were no significant differences in the total distance (SPS: F $(1,44)=$ $1.154, p=0.289$; ZIP: $\mathrm{F}(1,44)=1.365, p=0.249$; interaction between SPS and ZIP: F $(1,44)=0.0001, p=0.992)$ (Figure 3F).

One hour after OFT, the elevated plus maze test was applied. One-way ANOVA showed significant differences in the percentage of open arm time $(\mathrm{F}(2,33)=277.775$, $p<0.001)$ and the percentage of open arm entries ( $\mathrm{F}(2$, $33)=44.922, p<0.001$ ) among the groups (Figure 4A, B. Open Arm Time (s): Control group 52.3 \pm 1.33 ; SPS 7d group $20.7 \pm 0.91$; SPS 14d group $21.2 \pm 0.97$. Open Arm Entries: Control group $1.25 \pm 0.18$; SPS $7 d$ group $0.67 \pm$ 0.14 ; SPS $14 \mathrm{~d}$ group $0.83 \pm 0.17$ ). Post hoc comparison revealed that exposure of rats to SPS led to a reduction in OA duration and OA entries in both the SPS 7d $(p<0.001$, respectively) and SPS $14 \mathrm{~d}$ groups $(p<0.001$, respectively) compared with the unstressed control, indicating an increased anxiety behavior.

After ZIP injection, two-way ANOVA showed significant effects of SPS (F $(1,44)=166.766, p<0.001$; $\mathrm{F}(1,44)=42.666, p<0.001)$, ZIP $(\mathrm{F}(1,44)=119.016$, $p<0.001 ; \mathrm{F}(1,44)=11.926, p=0.001)$, and interaction between SPS and ZIP (F $(1,44)=93.678, p<0.001$; F $(1$, $44)=7.805, p=0.008)$ on the percentage of time spent in the open arms and the percentage of open arm entries (Figure 4C, D. Open Arm Time (s): Control + Saline group $53.3 \pm 1.21 ; \quad$ Control + ZIP group $55.0 \pm 1.37$; 


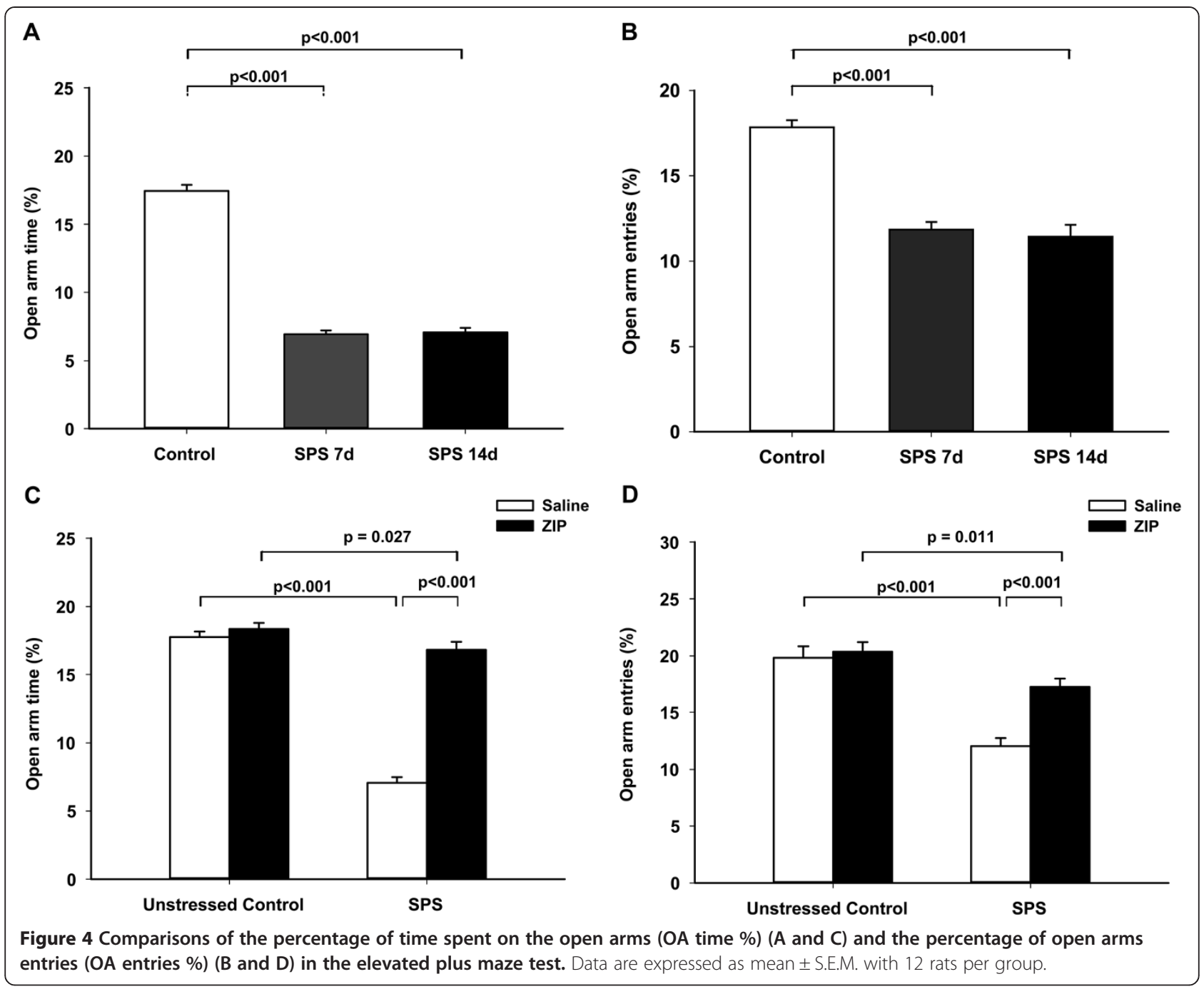

SPS + Saline group 21.2 \pm 1.28 ; SPS + ZIP group 50.4 \pm 1.76. Open Arm Entries: Control + Saline group $1.58 \pm$ 0.31 ; Control + ZIP group $1.67 \pm 0.26$; SPS + Saline group $0.83 \pm 0.17$; SPS + ZIP group $1.25 \pm 0.22$ ). Post hoc analysis revealed that ZIP treatment significantly increased the percentage of open arm time and the percentage of open arm entries in the SPS + ZIP group compared with the SPS + Saline group $(p<0.001$, respectively).

\section{Changes in the expression of $\mathrm{PKM} \zeta$ and $\mathrm{PKC} \zeta$}

The PKC $\zeta$, PKM $\zeta$ and GAPDH proteins were detected at 75,55 and $36 \mathrm{kDa}$, respectively (Figure $5 \mathrm{~A}$ ), and the mean values of the band densities of the control group were set as $100 \%$. The data were expressed as normalized ODs (Figure 5B). One-way ANOVA showed significant differences in the OD value of PKC $(\mathrm{F}(2,33)=$ $4.05, p=0.027)$. Post hoc comparison revealed that the OD value of the PKC $\zeta$ bands had a significant increase at 7 day in the SPS groups compared with the control group $(p=0.021)$, while there was no difference between
SPS 14d and the control groups $(p=0.263)$. The OD value of the PKM $\zeta$ bands had a significant increase at 7 and 14 days in the SPS groups compared with the control group ( $p<0.05$, one-way ANOVA). There were also significant differences in the OD value of PKM $(\mathrm{F}$ (2, $33)=68.018, p<0.001)$. Post hoc comparison revealed that both the SPS 7d group and the SPS 14d group had a significant increase in the OD value than the control group ( $p<0.001$, respectively).

To further confirm the changes in PKM caused by SPS exposure, Real-time RT-PCR analysis was performed (Figure 6). One-way ANOVA showed significant differences in the mRNA expression of PKM $(\mathrm{F}(2$, $15)=29.99, p<0.001)$. Post hoc comparison revealed that both the SPS 7d group and the SPS 14d group had a higher mRNA level than the control group $(p<0.001$, respectively). In the analysis of $\mathrm{PKC} \zeta$, one-way ANOVA showed significant differences in the mRNA expression of PKC $(\mathrm{F}(2,15)=5.503, p=0.016)$. Post hoc comparison revealed that the SPS 7d group had a higher mRNA 

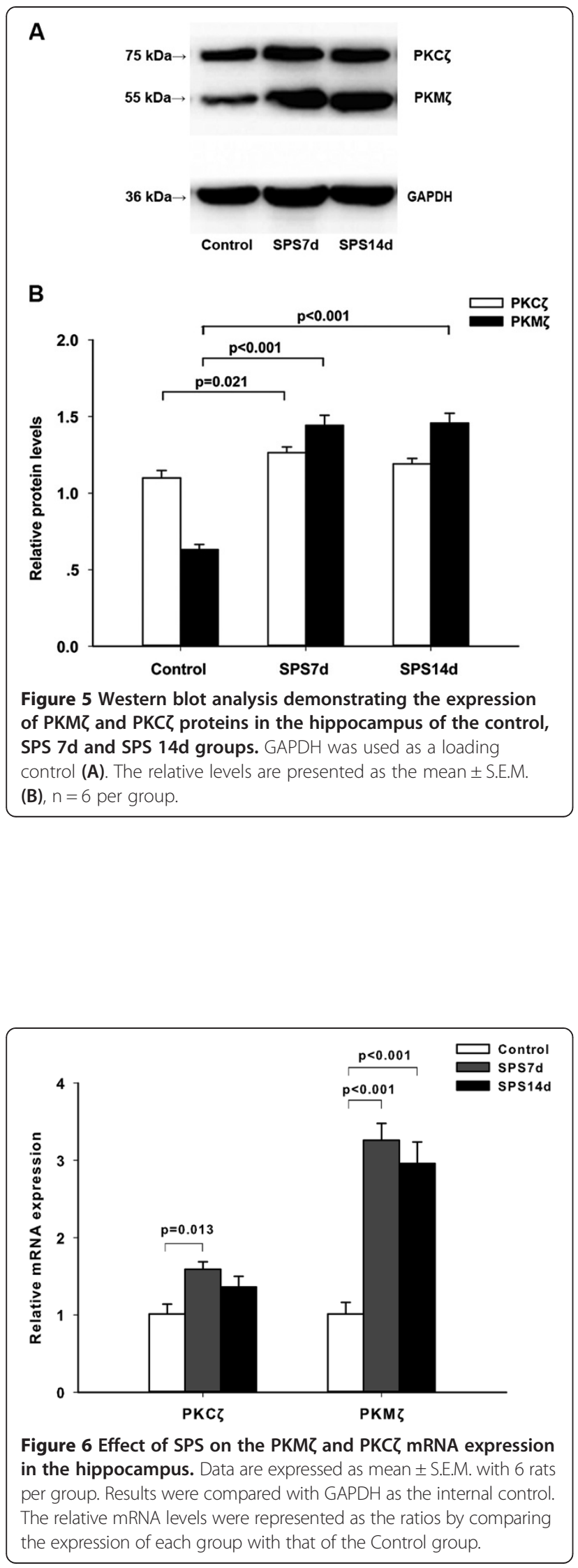

level than the control group ( $p=0.013)$, while there was no difference between SPS $14 \mathrm{~d}$ and the control groups $(p=0.15)$.

\section{Discussion}

In this study, rats subjected to SPS showed significantly enhanced depressive or anxiety-like behavior when restressed by re-exposure to the forced swim component of SPS. Meanwhile, there were significantly increased PKM levels compared with the control group. The additional FST at the end of SPS quiescent period differed from the conventionally used SPS protocol. After SPS, rats treated with ZIP prior to the trauma-related stressor displayed significantly shorter immobility time in the forced swim test compared with the vehicle group. The inactivation of PKM $\zeta$ with intra-hippocampal ZIP infusions effectively reduced PTSD-related behavioral abnormalities.

Although recent research in PTSD has yielded a number of important data, many issues concerning the etiopathogenisis remain elusive. In this context, the establishment of an appropriate animal model of PTSD is a prerequisite for better understanding of its mechanisms and the exploitation of more effective therapeutic intervention. Early animal models, like inescapable shock-learned helplessness models, though having good face validity, failed to reproduce the HPA axis changes characteristic of PTSD [17]. Although no ideal animal model of PTSD has been established to date, the single prolonged stress paradigm, proposed by Liberzon et al., has been widely accepted as a putative model for PTSD. SPS model successfully replicates several memory impairments found in PTSD patients, as well as pathophysiological characteristics, such as hypersensitive glucocorticoid feedback. Furthermore, SPS model has been demonstrated to replicate the inner neuroendocrine abnormality associated with PTSD [43]. However, studies using classical SPS protocol alone suggested that SPS might not increase anxiety-related behavior [44-48]; neither could it fully mimic the behavioral alterations without re-exposure to the context that PTSD patients frequently encountered. Antelman et.al. reported that stress-re-stress or a time dependent sensitization (TDS) model was a better paradigm for PTSD [49]. In this model, a single exposure to stress caused subsequent sensitization during the re-stress. Similarly, Harvey et al. used a modified SPS-re-stress paradigm to exhibit enhanced anxiety-related behavior by re-stressing rats with re-exposure to the forced swim component of SPS [44]. Thus, re-exposure to the FST procedure may serve as a trauma-related cue that enhances anxiety-related reactivity [50]. In the present study, we employed the modified SPS protocol. Our data showed enhanced depressive or anxiety-like behavior by re-exposure to the trauma-related stress, consistent with previous reports $[15,17,18,44,46,50]$. 
In addition, Wang et al. adopted a single inescapable electric foot shock at the end of SPS stressors, and observed an increase in anxiety-related behavior in the EPM [46,47]. Indeed, varient re-stress after SPS exposure has been demonstrated to be sufficient to produce long-lasting enhanced anxiety-like behavior [50,51].

Multiple lines of evidence indicate that PTSD is associated with memory impairment, as well as reduced hippocampal volumes and abnormal hippocampal function [5]. The hippocampus is responsible for explicit memory processes and context encoding during fear conditioning $[6,52,53]$. Importantly, the hippocampus seems to interact with the amygdala during the encoding of emotional memories [54-56], a process that is highly relevant to the study of PTSD. Hippocampus-related memory modulation in animals can result from intensive stressors or increased stress-associated hormones [5]. Extensive research has shown that stress is a potent modulator of learning and memory processes-including impairing and facilitating effects [57], which is possibly involved in the development of PTSD.

In the past few years, protein kinase $M$ zeta, which is expressed exclusively in neural tissue and enriched in the forebrain, has attracted intense interest for its putative role in memory maintenance. It lacks pseudosubstratedependent inhibition [58,59]. This potential autonomous activity suggests that PKM $\zeta$ might be an important player in LTP maintenance. Indeed, its activation enhances and its inhibition disrupts previously stored memories [60]. A wealth of subsequent work has indicated that inhibition of PKM $\zeta$ disrupts long-term memory in a wide range of brain organs, including the hippocampus, amygdala, and insular cortex [60]. The most commonly used inhibitor of PKM $\zeta$ is myristoylated zeta-pseudosubstrate inhibitory peptide, a synthetic peptide that mimics the pseudosubstrate sequence of PKC $[25,61]$, whereas recent work has raised concerns regarding both the role of PKM $\zeta$ in memory maintenance and the specificity of the pharmacological agent used to inhibit PKM $\zeta$ in those studies $[37,62]$. These results, however, do not convincingly exclude the possibility that $\mathrm{PKM} \zeta$ is a key player in memory maintenance [63], and PKM $\zeta$ still remains largely to be the target of ZIP infusions [42]. But unfortunately, previous studies commonly used a scrambled version of ZIP (Scr-ZIP) as a control peptide, which was demonstrated to be equally effective at reversing LTP as ZIP, or at least, weaken the memory to a certain degree [37]. On the contrary, the saline condition may be a more appropriate control for assessing the effects of PКM inhibition, as the animals in saline control routinely exhibited normal retention of conditioned fear [64].

As a result, the present study used saline injection as the control treatment, so as to avoid the vague role of ScrZIP. We showed that PKM increased one day after re-exposure to the trauma-related stressor. Inactivation of $\mathrm{PKM} \zeta$ with intra-hippocampal ZIP infusions effectively reduced PTSD-related behavioral abnormalities 7 days later, consistent with previous studies that have established the hippocampus as a key structure in context fear memory storage [65-70]. Alternatively, a number of contrary studies implied that the dorsal hippocampus was not an essential component in context fear storage [64]. In spite of the current debate, it is important to point out that the present study places emphasis on the effect of ZIP on the PTSD-like behavior by SPS exposure, rather than the erasure of existing memory. To the best of our knowledge, little literature is concerned with the effect of ZIP on PTSD symptom. Recently, Cohen et al. injected ZIP into four different brain structures after predator scent stress exposure, namely the dorsal hippocampus (DH), basolateral amygdala, lateral ventricle (LV) and insular cortex (IC) [71]. They reported that inactivation of $\mathrm{PKM} \zeta$ in the LV or DH within $1 \mathrm{~h}$ of exposure effectively reduced PTSD-like behavioral disruption and trauma cue response 8 days later, while inactivation of PKM 10 days after exposure had equivalent effects only when administered in the IC [71]. However, our results were not quite consistent with this comprehensive research. The discrepancy might due first to the different PTSD models applied. The predator scent stress exposure (PSS) model employed by Cohen et al. was comparatively different from the present re-stressed SPS model, which involved different neural circuit and might yield negative impact on the effectiveness of ZIP. Another possibility existed in the adoption of different control groups. As mentioned above, Volk et al. has demonstrated that Scr-ZIP plays a role in the memory disruption to a certain degree [37]. Therefore, Scr-ZIP might not be the most appropriate control for ZIP from the current point of view, which would consequently be hard to make a peer to peer comparison.

In conclusion, the results of the present study demonstrate that intro-hippocampal administration of ZIP after re-stressed SPS effectively alleviates depressive and anxiety-like behavioral abnormalities, and PKM $\zeta$ might be involved in the development of PTSD. Continued evidence for the controversial mechanism of ZIP will highlight its potential use in a wide range of psychiatric disorders.

\section{Competing interest}

The authors declare that they have no competing interest.

\section{Authors' contributions}

$L-L J$ and Z-YW designed the study, wrote the protocol and supervised its execution. B-KX and C-HF worked rat SPS model and isolated the samples. WS and J-BP performed the surgery and behavior test. LT undertook statistical analyses and constructed the figures and table; $L-L J$ composed the first draft of this manuscript. All authors contributed to and have approved the final manuscript. 


\section{Role of funding source}

This work was supported by grants from Research Fund for Socia Development of Science and Technology of Liaoning Province, China (No. 2012225021), and the Natural Science Foundation of China (No. 31100793).

\section{Author details}

'Department of Anatomy, College of Basic Medical Sciences, China Medical University, Shenyang 110001, People's Republic of China. ${ }^{2}$ College of Clinical Medicine, China Medical University, Shenyang 110001, People's Republic of China

Received: 17 March 2014 Accepted: 13 August 2014

Published: 1 September 2014

\section{References}

1. Takahashi T, Morinobu S, Iwamoto Y, Yamawaki S: Effect of paroxetine on enhanced contextual fear induced by single prolonged stress in rats. Psychopharmacol (Berl) 2006, 189:165-173.

2. Brunello N, Davidson JR, Deahl M, Kessler RC, Mendlewicz J, Racagni G, Shalev AY, Zohar J: Posttraumatic stress disorder: diagnosis and epidemiology, comorbidity and social consequences, biology and treatment. Neuropsychobiol 2001, 43:150-162.

3. Nemeroff CB, Bremner JD, Foa EB, Mayberg HS, North CS, Stein MB: Posttraumatic stress disorder: a state-of-the-science review. J Psychiatr Res 2006, 40:1-21.

4. Heimer L, Van Hoesen GW: The limbic lobe and its output channels: implications for emotional functions and adaptive behavior. Neurosci Biobehav Rev 2006, 30:126-147.

5. Shin LM, Rauch SL, Pitman RK: Amygdala, medial prefrontal cortex, and hippocampal function in PTSD. Ann N Y Acad Sci 2006, 1071:67-79.

6. Maren S: Fear of the unexpected: Hippocampus mediates noveltyinduced return of extinguished fear in rats. Neurobiol Learn Mem 2014, 108:88-95.

7. Maren S, Phan KL, Liberzon I: The contextual brain: implications for fear conditioning, extinction and psychopathology. Nat Rev Neurosci 2013, 14:417-428

8. Knapska E, Macias M, Mikosz M, Nowak A, Owczarek D, Wawrzyniak M, Pieprzyk M, Cymerman IA, Werka T, Sheng M, Maren S, Jaworski J, Kaczmarek L: Functional anatomy of neural circuits regulating fear and extinction. Proc Natl Acad Sci U S A 2012, 109:17093-17098.

9. Bremner JD, Randall P, Scott TM, Bronen RA, Seibyl JP, Southwick SM, Delaney RC, McCarthy G, Charney DS, Innis RB: MRI-based measurement of hippocampal volume in patients with combat-related posttraumatic stress disorder. Am J Psychiatry 1995, 152:973-981.

10. Pavic L, Gregurek R, Rados M, Brkljacic B, Brajkovic L, Simetin-Pavic I, Ivanac G, Pavlisa G, Kalousek V: Smaller right hippocampus in war veterans with posttraumatic stress disorder. Psychiatry Res 2007, 154:191-198.

11. Woon FL, Sood S, Hedges DW: Hippocampal volume deficits associated with exposure to psychological trauma and posttraumatic stress disorder in adults: a meta-analysis. Prog Neuropsychopharmacol Biol Psychiatry 2010, 34:1181-1188.

12. Smith ME: Bilateral hippocampal volume reduction in adults with post-traumatic stress disorder: a meta-analysis of structural MRI studies. Hippocampus 2005, 15:798-807

13. Gilbertson MW, Shenton ME, Ciszewski A, Kasai K, Lasko NB, Orr SP, Pitman RK: Smaller hippocampal volume predicts pathologic vulnerability to psychological trauma. Nat Neurosci 2002, 5:1242-1247.

14. Liberzon I, Young EA: Effects of stress and glucocorticoids on CNS oxytocin receptor binding. Psychoneuroendocrinology 1997, 22:411-422.

15. Khan S, Liberzon I: Topiramate attenuates exaggerated acoustic startle in an animal model of PTSD. Psychopharmacol (Berl) 2004, 172:225-229.

16. Iwamoto Y, Morinobu S, Takahashi T, Yamawaki S: Single prolonged stress increases contextual freezing and the expression of glycine transporter 1 and vesicle-associated membrane protein 2 mRNA in the hippocampus of rats. Prog Neuropsychopharmacol Biol Psychiatry 2007, 31:642-651.

17. Liberzon I, Krstov M, Young EA: Stress-restress: effects on ACTH and fast feedback. Psychoneuroendocrinol 1997, 22:443-453.

18. Imanaka A, Morinobu S, Toki S, Yamawaki S: Importance of early environment in the development of post-traumatic stress disorder-like behaviors. Behav Brain Res 2006, 173:129-137.
19. Yamamoto S, Morinobu S, Takei S, Fuchikami M, Matsuki A, Yamawaki S, Liberzon I: Single prolonged stress: toward an animal model of posttraumatic stress disorder. Depress Anxiety 2009, 26:1110-1117.

20. Knox D, George SA, Fitzpatrick CJ, Rabinak CA, Maren S, Liberzon I: Single prolonged stress disrupts retention of extinguished fear in rats. Learn Mem 2012, 19:43-49.

21. Maren S: Nature and causes of the immediate extinction deficit: A brief review. Neurobiol Learn Mem 2014, 113:19-24.

22. Fitzgerald PJ, Seemann JR, Maren S: Can fear extinction be enhanced? A review of pharmacological and behavioral findings. Brain Res Bull 2014, 105:46-60.

23. Orsini $C A$, Maren S: Neural and cellular mechanisms of fear and extinction memory formation. Neurosci Biobehav Rev 2012, 36:1773-1802.

24. Milad MR, Pitman RK, Ellis CB, Gold AL, Shin LM, Lasko NB, Zeidan MA, Handwerger K, Orr SP, Rauch SL: Neurobiological basis of failure to recall extinction memory in posttraumatic stress disorder. Biol Psychiatry 2009, 66:1075-1082.

25. Ling DS, Benardo LS, Serrano PA, Blace N, Kelly MT, Crary JF, Sacktor TC: Protein kinase Mzeta is necessary and sufficient for LTP maintenance. Nat Neurosci 2002, 5:295-296

26. Pastalkova E, Serrano P, Pinkhasova D, Wallace E, Fenton AA, Sacktor TC: Storage of spatial information by the maintenance mechanism of LTP. Science 2006, 313:1141-1144

27. Shema R, Sacktor TC, Dudai Y: Rapid erasure of long-term memory associations in the cortex by an inhibitor of PKM zeta. Science 2007. 317:951-953

28. Serrano P, Friedman EL, Kenney J, Taubenfeld SM, Zimmerman JM, Hanna J, Alberini C, Kelley AE, Maren S, Rudy JW, Yin JC, Sacktor TC, Fenton AA: PKMzeta maintains spatial, instrumental, and classically conditioned long-term memories. PLOS Biol 2008, 6:2698-2706.

29. Migues PV, Hardt O, Wu DC, Gamache K, Sacktor TC, Wang YT, Nader K: PKMzeta maintains memories by regulating GluR2-dependent AMPA receptor trafficking. Nat Neurosci 2010, 13:630-634.

30. Shema R, Haramati S, Ron S, Hazvi S, Chen A, Sacktor TC, Dudai Y: Enhancement of consolidated long-term memory by overexpression of protein kinase Mzeta in the neocortex. Science 2011, 331:1207-1210.

31. Song MJ, Jang JK, Kim WY, Yoon HS, Kim JH: Inhibition of PKMzeta in the nucleus accumbens core blocks the expression of locomotor sensitization induced by amphetamine. Behav Brain Res 2013, 241:139-143.

32. Gamiz F, Gallo M: Intra-amygdala ZIP injections impair the memory of learned active avoidance responses and attenuate conditioned taste-aversion acquisition in rats. Learn Mem 2011, 18:529-533.

33. He YY, Xue YX, Wang JS, Fang Q, Liu JF, Xue LF, Lu L: PKMzeta maintains drug reward and aversion memory in the basolateral amygdala and extinction memory in the infralimbic cortex. Neuropsychopharmacol 2011, 36:1972-1981.

34. Parsons RG, Davis M: Temporary disruption of fear-potentiated startle following PKMzeta inhibition in the amygdala. Nat Neurosci 2011 14:295-296

35. Kwapis JL, Jarome TJ, Gilmartin MR, Helmstetter FJ: Intra-amygdala infusion of the protein kinase Mzeta inhibitor ZIP disrupts foreground context fear memory. Neurobiol Learn Mem 2012, 98:148-153.

36. Yao Y, Shao C, Jothianandan D, Tcherepanov A, Shouval H, Sacktor TC Matching biochemical and functional efficacies confirm ZIP as a potent competitive inhibitor of PKMzeta in neurons. Neuropharmacol 2013, 64:37-44.

37. Volk LJ, Bachman JL, Johnson R, Yu Y, Huganir RL: PKM-zeta is not required for hippocampal synaptic plasticity, learning and memory. Nature 2013, 493:420-423.

38. Wu-Zhang AX, Schramm CL, Nabavi S, Malinow R, Newton AC: Cellular pharmacology of protein kinase Mzeta (PKMzeta) contrasts with its in vitro profile: implications for PKMzeta as a mediator of memory. J Biol Chem 2012, 287:12879-12885.

39. Sacktor TC: How does PKMzeta maintain long-term memory? Nat Rev Neurosci 2011, 12:9-15.

40. Lisman J: Memory erasure by very high concentrations of ZIP may not be due to PKM-zeta. Hippocampus 2012, 22:648-649.

41. Li YQ, Xue YX, He YY, Li FQ, Xue LF, Xu CM, Sacktor TC, Shaham Y, Lu L: Inhibition of PKMzeta in nucleus accumbens core abolishes long-term drug reward memory. J Neurosci 2011, 31:5436-5446. 
42. Kwapis JL, Helmstetter FJ: Does PKM(zeta) maintain memory? Brain Res Bull 2014, 105:36-45

43. George SA, Knox D, Curtis AL, Aldridge JW, Valentino RJ, Liberzon I: Altered locus coeruleus-norepinephrine function following single prolonged stress. Eur J Neurosci 2013, 37:901-909.

44. Harvey BH, Brand L, Jeeva Z, Stein DJ: Cortical/hippocampal monoamines, HPA-axis changes and aversive behavior following stress and restress in an animal model of post-traumatic stress disorder. Physiol Behav 2006, 87:881-890

45. Peng Y, Feng SF, Wang Q, Wang HN, Hou WG, Xiong L, Luo ZJ, Tan QR: Hyperbaric oxygen preconditioning ameliorates anxiety-like behavior and cognitive impairments via upregulation of thioredoxin reductases in stressed rats. Prog Neuropsychopharmacol Biol Psychiatry 2010, 34:1018-1025

46. Wang $W$, Liu Y, Zheng $H$, Wang HN, Jin $X$, Chen YC, Zheng LN, Luo XX, Tan QR: A modified single-prolonged stress model for post-traumatic stress disorder. Neurosci Lett 2008, 441:237-241.

47. Wang HN, Peng Y, Tan QR, Chen YC, Zhang RG, Qiao YT, Wang HH, Liu L, Kuang F, Wang BR, Zhang ZJ: Quetiapine ameliorates anxiety-like behavior and cognitive impairments in stressed rats: implications for the treatment of posttraumatic stress disorder. Physiol Res 2010, 59:263-271.

48. Wang HT, Han F, Gao JL, Shi YX: Increased phosphorylation of extracellular signal-regulated kinase in the medial prefrontal cortex of the single-prolonged stress rats. Cell Mol Neurobiol 2010, 30:437-444.

49. Yehuda R, Antelman SM: Criteria for rationally evaluating animal models of posttraumatic stress disorder. Biol Psychiatry 1993, 33:479-486.

50. Eagle AL, Knox D, Roberts MM, Mulo K, Liberzon I, Galloway MP, Perrine SA: Single prolonged stress enhances hippocampal glucocorticoid receptor and phosphorylated protein kinase B levels. Neurosci Res 2013, 75:130-137.

51. Korte SM, De Boer SF, Bohus B: Fear-potentiation in the elevated plus-maze test depends on stressor controllability and fear conditioning. Stress 1999, 3:27-40.

52. Corcoran KA, Maren S: Hippocampal inactivation disrupts contextual retrieval of fear memory after extinction. J Neurosci 2001, 21:1720-1726.

53. Eichenbaum $\mathrm{H}$ : A cortical-hippocampal system for declarative memory. Nat Rev Neurosci 2000, 1:41-50.

54. Dolcos F, LaBar KS, Cabeza R: Interaction between the amygdala and the medial temporal lobe memory system predicts better memory for emotional events. Neuron 2004, 42:855-863.

55. McGaugh JL: The amygdala modulates the consolidation of memories of emotionally arousing experiences. Annu Rev Neurosci 2004, 27:1-28.

56. Orsini CA, Yan C, Maren S: Ensemble coding of context-dependent fear memory in the amygdala. Front Behav Neurosci 2013, 7:199.

57. Sandi C, Pinelo-Nava MT: Stress and memory: behavioral effects and neurobiological mechanisms. Neural Plast 2007, 2007:78970.

58. Hernandez Al, Blace N, Crary JF, Serrano PA, Leitges M, Libien JM, Weinstein G, Tcherapanov A, Sacktor TC: Protein kinase M zeta synthesis from a brain mRNA encoding an independent protein kinase $C$ zeta catalytic domain. Implications for the molecular mechanism of memory. J Biol Chem 2003, 278:40305-40316.

59. Sacktor TC, Osten P, Valsamis H, Jiang X, Naik MU, Sublette E: Persistent activation of the zeta isoform of protein kinase $C$ in the maintenance of long-term potentiation. Proc Natl Acad Sci U S A 1993, 90:8342-8346.

60. Sacktor TC, Fenton AA: Appropriate application of ZIP for PKMzeta inhibition, LTP reversal, and memory erasure. Hippocampus 2012, 22:645-647

61. Li XY, Ko HG, Chen T, Descalzi G, Koga K, Wang H, Kim SS, Shang Y, Kwak C, Park SW, Shim J, Lee K, Collingridge GL, Kaang BK, Zhuo M: Alleviating neuropathic pain hypersensitivity by inhibiting PKMzeta in the anterior cingulate cortex. Science 2010, 330:1400-1404

62. Lee AM, Kanter BR, Wang D, Lim JP, Zou ME, Qiu C, McMahon T, Dadgar J, Fischbach-Weiss SC, Messing RO: Prkcz null mice show normal learning and memory. Nature 2013, 493:416-419.

63. Frankland PW, Josselyn SA: NEUROSCIENCE Memory and the single molecule. Nature 2013, 493:312-313.

64. Kwapis JL, Jarome TJ, Lonergan ME, Helmstetter FJ: Protein kinase Mzeta maintains fear memory in the amygdala but not in the hippocampus. Behav Neurosci 2009, 123:844-850.

65. Kim JJ, Fanselow MS: Modality-specific retrograde amnesia of fear. Science 1992, 256:675-677
66. Matus-Amat $P$, Higgins EA, Barrientos RM, Rudy JW: The role of the dorsal hippocampus in the acquisition and retrieval of context memory representations. J Neurosci 2004, 24:2431-2439.

67. Rudy JW, O'Reilly RC: Conjunctive representations, the hippocampus, and contextual fear conditioning. Cogn Affect Behav Neurosci 2001, 1:66-82.

68. Yoshihama Y, Hirai T, Ohtsuka T, Chida K: KIBRA Co-localizes with protein kinase Mzeta (PKMzeta) in the mouse hippocampus. Biosci Biotechnol Biochem 2009, 73:147-151.

69. Hardt O, Migues PV, Hastings M, Wong J, Nader K: PKMzeta maintains 1-day- and 6-day-old long-term object location but not object identity memory in dorsal hippocampus. Hippocampus 2010, 20:691-695.

70. Monti MC, Gabach LA, Perez MF, Ramirez OA: Impact of contextual cues in the expression of the memory associated with diazepam withdrawal: involvement of hippocampal PKMzetain vivo, and Arc expression and LTP in vitro. Eur J Neurosci 2012, 36:3118-3125.

71. Cohen H, Kozlovsky N, Matar MA, Kaplan Z, Zohar J: Mapping the brain pathways of traumatic memory: inactivation of protein kinase $M$ zeta in different brain regions disrupts traumatic memory processes and attenuates traumatic stress responses in rats. Eur Neuropsychopharmacol 2010, 20:253-271.

doi:10.1186/1744-9081-10-28

Cite this article as: Ji et al:: Intra-hippocampal administration of ZIP alleviates depressive and anxiety-like responses in an animal model of posttraumatic stress disorder. Behavioral and Brain Functions 2014 10:28

\section{Submit your next manuscript to BioMed Central and take full advantage of:}

- Convenient online submission

- Thorough peer review

- No space constraints or color figure charges

- Immediate publication on acceptance

- Inclusion in PubMed, CAS, Scopus and Google Scholar

- Research which is freely available for redistribution

Submit your manuscript at www.biomedcentral.com/submit
C Biomed Central 